\title{
EXPERIMENTAL INVESTIGATION OF THE EFFECTS OF WINGLETS ON THE TIP VORTEX BEHAVIOR OF A MODEL HORIZONTAL AXIS WIND TURBINE USING PARTICLE IMAGE VELOCIMETRY
}

\section{Yaşar Ostovan ${ }^{1}$, M. Tuğrul Akpolat ${ }^{2}$, and Ŏguz $\mathrm{Uzol}^{3}$}

1 Ph.D., Dept. of Aerospace Engineering, METU Center for Wind Energy, Middle East Technical University (METU), 06800, Ankara, TURKEY, Currently Research Engineer at Laboratoire des Fluides de Lille Kampe de Feriet (LMFL), 59650, Villeneuve d'Ascq, FRANCE, E-Mail: yasar.ostovan@centralelille.fr

2 Ph.D. candidate, Dept. of Aerospace Engineering, METU Center for Wind Energy, Middle East Technical University (METU), 06800,Ankara, TURKEY, E-Mail: tugrul.akpolat@metu.edu.tr

3 Corresponding Author: Associate Professor, Department of Aerospace Engineering, METU Center for Wind Energy, Middle East Technical University (METU), 06800, Ankara, TURKEY, E-Mail: uzol@metu.edu.tr, Tel: +90 31274 66, Fax: +90 31221079

\begin{abstract}
This study presents an experimental investigation on the effects of winglets on the near wake flow around the tip region and on the tip vortex characteristics downstream of a $0.94 \mathrm{~m}$ diameter threebladed horizontal axis wind turbine rotor. Phase-locked 2D PIV measurements are performed with and without winglets covering 120 degrees of azimuthal progression of the rotor. The impact of using winglets on the flow field near the wake boundary as well as on the tip vortex characteristics such as the vortex convection, vortex core size and core expansion as well as the resultant induced drag on the rotor are investigated. Results show that winglets initially generate an asymmetric co-rotating vortex pair, which eventually merge together after about 10 tip chords downstream to create a single but nonuniform vortex structure. Mutual induction of the initial double vortex structure causes a faster downstream convection and a radially outward motion of tip vortices compared to the baseline case.
\end{abstract}


The wake boundary is shifted radially outwards, velocity gradients are diffused, vorticity and turbulent kinetic energy levels are significantly reduced across the wake boundary. The tip vortex core sizes are three times as big compared to those of the baseline case and within the vortex core, vorticity and turbulent kinetic energy levels are reduced more than 50\%. Results show consistency with various vortex core and expansion models albeit with adjusted model coefficients for the winglet case. The estimated induced drag reduction is about $15 \%$ when winglets are implemented.

\section{KEYWORDS}

tip vortex, winglets, wind turbine wakes, particle image velocimetry

\section{NOMENCLATURE}

c rotor blade tip chord length

\section{HAWT Horizontal Axis Wind Turbine}

$k \quad$ turbulent kinetic energy

$<k>\quad$ overall average turbulent kinetic energy

PIV Particle Image Velocimetry

$r \quad$ radial distance from vortex core center

$r_{c} \quad$ vortex core radius

$S_{c} \quad$ time offset

$t \quad$ time

TSR Tip Speed Ratio

$\bar{u} \quad$ phase average axial velocity

$\langle\bar{u}\rangle \quad$ overall average axial velocity 


$\begin{array}{ll}\overline{u_{v}} & \text { phase average vortex induced axial velocity } \\ \bar{u}_{\text {core }} & \text { average vortex core convection axial velocity } \\ \overline{v_{v}} & \text { phase average vortex induced lateral velocity } \\ \bar{v}_{\text {core }} & \text { average vortex core convection lateral velocity } \\ V_{\theta} & \text { vortex induced swirl (tangential) velocity } \\ x^{\prime} & \text { x coordinate with the blade tip at the origin } \\ y^{\prime} & \text { y coordinate with the blade tip at the origin } \\ \Gamma_{\infty} & \text { vortex circulation in the far field } \\ \delta_{v} & \text { turbulent viscosity coefficient } \\ \bar{\Omega}_{\infty} & \text { averall average out-of-plane vorticity } \\ \rho_{z} & \text { ain density } \\ & \end{array}$

\section{INTRODUCTION}

Using winglets at wing tips not only reduces the induced drag but also reduces the strength of tip vortices [1]. Despite these known benefits in fixed wing aircraft, winglet applications in commercial wind turbines are not as common and the research is rather limited in open literature.

Numerical and experimental studies on the effects of winglets on wind turbine power and thrust performance generally show that properly designed winglets can have a positive impact on the power performance. However, this gain comes with an increase in thrust coefficient of the turbine. Johansen 
and Sorensen [2] numerically investigated the effects of several winglet designs on the power performance of a modern wind turbine. The winglets had similar heights and cant angles but different airfoils and twist angles. The maximum increasing effect on the power performance was $1.71 \%$ that resulted in a $1.81 \%$ increase in the thrust coefficient. For some TSR values, winglets caused a reduction of the power of the turbine while thrust was always increasing. Gaunna and Johansen [3] showed, using CFD simulations, that their best winglet design has $1.74 \%$ and $2.80 \%$ increase in power and thrust coefficients, respectively. They also showed that downwind winglets are more efficient than upwind ones of the same height (a downwind winglet bends towards the suction side of a blade). Upwind winglets are expected to contract the wake while the downwind winglets are supposed to cause the wake to expand [2]. In measurements of Gertz et al. [4], a designed set of winglets increased the power of a $3.3 \mathrm{~m}$ diameter model wind turbine up to $6 \%$ over the central part of the operating range of the turbine while reducing it elsewhere. In another study, Elfarra et al. [5] designed an optimized winglet for NREL Phase VI wind turbine using CFD. The optimized winglet achieved around 9\% increase in the power production. Tobin et al. [6] looked at the effect of winglets on the aerodynamic performance of a model turbine with a rotor diameter of $0.12 \mathrm{~m}$. Results showed that power and thrust coefficients increased about $8.2 \%$ and $15.0 \%$, respectively. Authors suggested a possible positive tradeoff between power and thrust coefficients at a wind farm scale by using a simple theoretical treatment of a two-turbine system. They also conducted PIV measurements up to 5D downstream with and without winglets attached. Their experiments showed that the winglets did not significantly change the tip-vortex strength, suggesting that the aerodynamic improvements came from a downwind shift in the tip-vortex structure rather than diminishing its magnitude. Shimizu et al. [7] and Abdulrahim et al. [8] has experimentally shown that Mie-vane type tip devices can also have positive effects on the power performance of wind turbines. Effects of winglets used in the current study on the power and thrust coefficients of the model wind turbine have been investigated 
previously by the authors [9]. Results show that for the turbine running near design TSR of 6 , power and thrust coefficients increase about $4.2 \%$ and $6.5 \%$, respectively.

Although it has been shown in the literature that the winglets have the potential to increase the power performance of turbines especially near design conditions, the effects on the tip vortex and wake characteristics are less clear. Most of the numerical and experimental studies on the tip vortex characteristics focus on wind turbines with no tip devices. For example, laser sheet visualization (LSV) technique was used by Grant et al. [10] to picture the trajectories of the trailing vorticity under several conditions of turbine yaw and rotor azimuth with a rotor diameter of $0.9 \mathrm{~m}$. Results were compared with a wake model highlighting the effects of wind tunnel walls that should be numerically represented in the wake model. Xiao et al. [11] experimentally investigated the initiation and development of the tip vortex for a model HAWT using Particle Image Velocimetry. Results showed that the tip vortex first moves inward for a very short period and then moves outward with the wake expansion. The downstream movement of the tip vortex was depicted to be nearly linear in the very near wake region. Massouh and Dobrev [12] conducted an experimental study on the flow characteristics of the near wake of a model HAWT with a rotor diameter of $0.5 \mathrm{~m}$. PIV region of interest contained vortex ages $0^{\circ}$ to $810^{\circ}$ showing that the vortex wandering motion increased significantly as the vortices aged downstream of the rotor. Moreover, it was concluded that the vortex characteristics such as vortex core diameter, the swirl velocity distribution and the vortex diffusion obtained from data were quite different from those obtained for model helicopter rotor.

Due to the complexity of the flow field in the wind turbine wake region, particularly regarding the dominant tip vortex structures at the outer region of the wake, numerical simulation of the flow field downstream of the turbine rotor is still a challenge. Therefore, reliable experimental data are critical to support such efforts. The current study presents an experimental investigation focusing on the effects of winglets on the near wake flow around the tip region and on the tip vortex characteristics within the wake. Phase-locked two-dimensional Particle Image Velocimetry (PIV) measurements are performed 
downstream of a $0.94 \mathrm{~m}$ diameter three-bladed horizontal axis wind turbine, with and without winglets, following 120 degrees of azimuthal progression of the rotor. Details of the flow field are presented as phase-locked and overall averages (i.e. averages of phase-locked data). The impact of using winglets on the tip vortex structure in terms of its downstream convection, vortex core size and core expansion characteristics as well as induced velocity field, vorticity and turbulent kinetic energy around the vortex core are presented in detail using the PIV data.

\section{EXPERIMENTAL SETUP AND MEASUREMENT DETAILS}

Measurements are conducted in the open jet facility of METU Center for Wind Energy, which has a jet exit diameter of $1.7 \mathrm{~m}$. A three-bladed model HAWT with a rotor diameter of $0.94 \mathrm{~m}$ is placed 0.5 rotor diameter downstream of the tunnel jet exit (Figure 1). The measurements are conducted in the potential core of the jet exit where the turbine is sufficiently far away from the jet boundaries and the jet shear layer. Therefore, one should note that the turbine is subjected to uniform inlet velocity conditions, which is of course not representative of real flow conditions where the turbine operates in an oncoming atmospheric boundary layer. The uniform inflow allowed us to focus on the fundamental differences in the flow field near the tip between winglet and non-winglet cases. In the case of flow with inlet mean shear, the winglet design should take in to account the change in the incoming velocity at different rotor azimuthal positions.

Figure 2 shows the inlet flow velocity distribution around the rotor tip and the corresponding turbulence intensity distribution measured using hot-wire anemometry along radial direction. The radial distance is non-dimensionalized with rotor radius $(\mathrm{R})$, therefore $\mathrm{r} / \mathrm{R}=1$ is the rotor tip. Also, $\mathrm{r} / \mathrm{R}=1.8$ corresponds the actual tunnel boundary. As is evident from the figure the inlet flow near the rotor tip position is quite uniform with a velocity variation less than $0.4 \mathrm{~m} / \mathrm{s}$, which is about $3 \%$ of the freestream velocity. The average turbulence intensity level is around $2.5 \%$. The effect of the tunnel boundary is also observable as reduced velocity and increased turbulence due to the open jet shear 
layer. Nevertheless it can be seen that this region is sufficiently separated from the rotor tip where the PIV measurements are conducted.

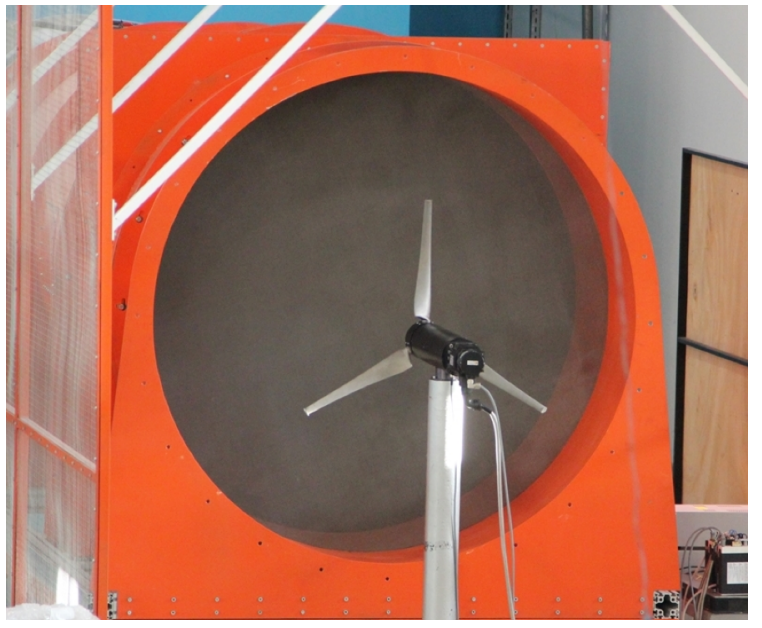

(a)

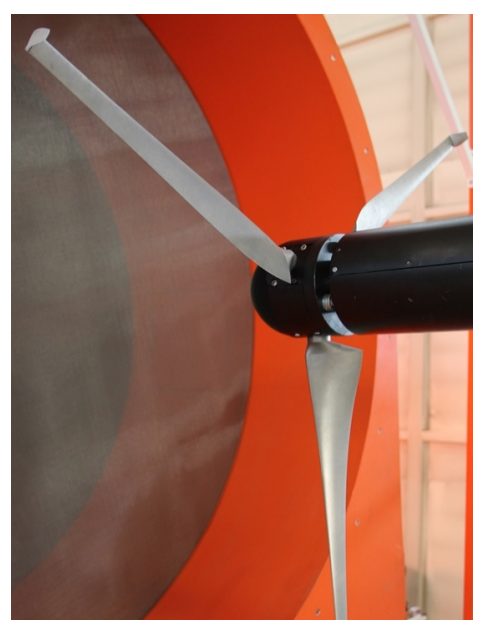

(b)

Figure 1. (a) Model wind turbine located at the jet exit of the open jet wind tunnel and (b) the winglets attached to blade tips of the turbine.

Note that the experiments are performed at a single freestream turbulence level of $2.5 \%$, which is significantly lower than real life conditions, and therefore the experimental conditions could be considered as an ideal scenario. Investigation of the effects of turbulence is out of the scope of this paper and we will present results on this problem in our future publications.

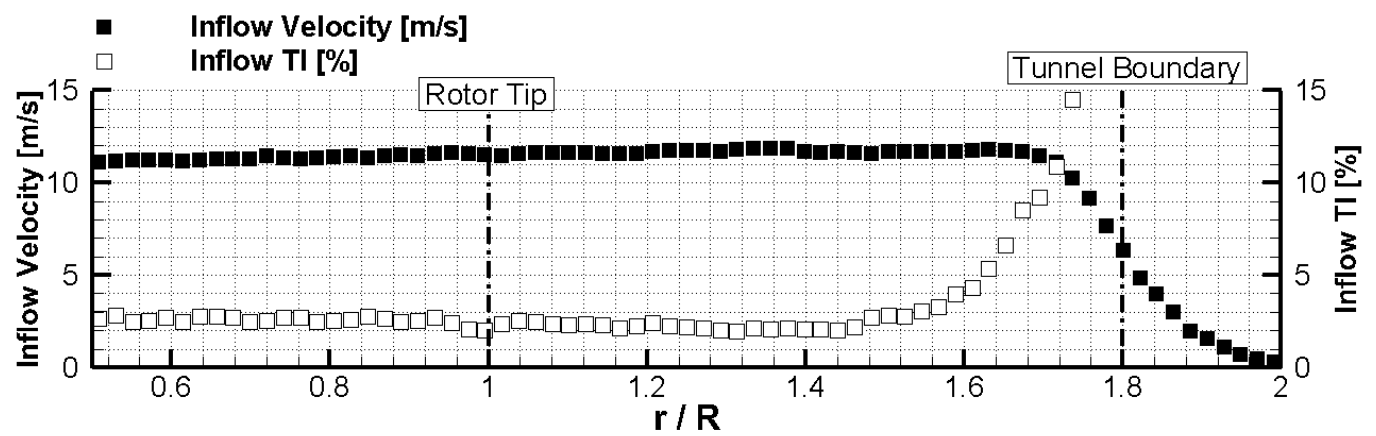

Figure 2 Inlet velocity and turbulence intensity distributions $0.5 \mathrm{D}$ downstream of the open jet tunnel. Here $\mathrm{R}$ is the rotor radius. The rotor tip and the tunnel boundary positions are indicated on the image.

The rotor blades are non-linearly twisted and tapered and use NREL S826 profile along the span. This rotor design was used in a series blind test wind tunnel campaigns in previous studies, and more details about the rotor design can be found in [13-16]. The rotational velocity of the rotor is precisely 
controlled through a servo motor. The RPM variation of the motor during a typical experiment was about $0.1 \%$, which corresponds to about $0.01^{\circ}$ variation in a selected phase. A torque meter on the rotating shaft measures the net torque created by the wind turbine rotor. To match the desired Tip Speed Ratio (TSR) at a selected free stream wind speed, the turbine is rotated at the corresponding rpm values. More details about the system can be found in $[17,18]$.

A set of downwind winglets is designed and manufactured from aluminum using 3D printing techniques. Winglet profile is selected as PSU 94-097, which is an airfoil designed for use on winglets for low-speed airplanes. Cant, toe, twist and sweep angles are selected as $90^{\circ}, 1^{\circ},-0.5^{\circ}$ and $19^{\circ}$, respectively, as shown in Figure 3. This profile and these variables were appropriate for the Reynolds number range of the current wind turbine during the experiments when operating at design TSR of 6 [19]. The height of the winglet is selected as $6 \%$ of the rotor radius. A picture of the winglets attached to the turbine blades can be seen in Figure $1 \mathrm{~b}$. The PIV system consists of a $120 \mathrm{~mJ} / \mathrm{pulse} \mathrm{Nd}$ :YAG laser and a Phantom v640 camera with a maximum resolution of $2560 \times 1600$ pixels. Proper optics are used to guide the laser beam to the hub height of the turbine and convert it to a laser sheet aligned with the free stream flow and passed through the central axes of the rotor. A hall-effect sensor attached to the turbine hub sends a one-per-rev signal to the synchronizer box. The laser and the camera can then be triggered at predetermined azimuthal positions of the rotor by selecting a proper trigger time

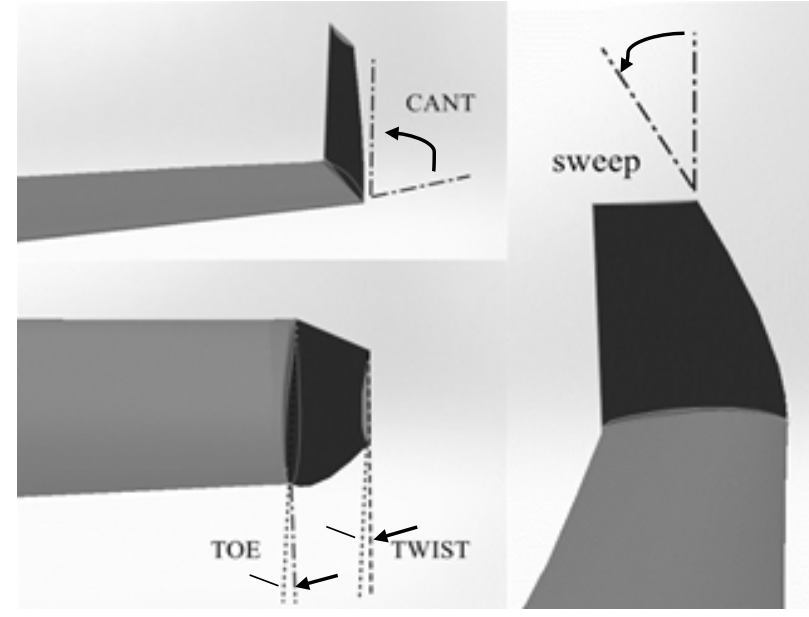

Figure 3 Definitions of winglet design variables. 
delay. The experiments are conducted at 21 different azimuthal positions of the rotor between $0^{\circ}$ and $120^{\circ}$ phase angles with 6 -degree intervals. Figure 4a shows the phase definitions and sample three phases of the rotor. Phase $0^{\circ}$ is defined as the azimuthal position of the rotor in which the laser cuts blade\#1 tip from the mid-chord as shown in Figure 4a.

PIV measurement domain near the blade tip is shown in Figure 4b. It consists of two identical measurement windows with an area of $228 \mathrm{~mm} \times 141 \mathrm{~mm}$. The overlap region of two windows is $10 \%$ that results in a total measurement area of $436 \mathrm{~mm} \times 141 \mathrm{~mm}$. A 3D traverse system adjusts the position of the camera with respect to the laser sheet.

Laser sheet thickness is about $2 \mathrm{~mm}$ at the PIV measurement domain. This thickness is about $35 \%$ of the interrogation area size, which is $64 \times 64$ pixels $^{2}$ ( 64 pixels $\left.=5.76 \mathrm{~mm}\right)$. Using the measured $\mathrm{C}_{\mathrm{T}}$ value at tip-speed-ratio equal to 6 and the momentum theory with wake rotation, the out-of-plane velocity is estimated to be $0.62 \mathrm{~m} / \mathrm{s}$, i.e. $5.6 \%$ of the freestream wind speed. For $25 \mu \mathrm{s}$ time interval between exposures of phase-locked measurements, this also satisfies the condition that out-of-plane displacement should be less than $1 / 4^{\text {th }}$ of the laser sheet thickness while providing good enough particle density within the interrogation volume [20,21].

For each measurement window and each phase, 1000 image pairs are recorded to obtain converged statistics $[22,23]$. Figure 5 shows a convergence plot for two measured velocity components as well as for turbulent kinetic energy using samples from a grid point in window 1, for phase 90 and near the vortex core where turbulence levels are high. It is evident that 1000 vector maps provide converged statistics both for first and second order moments. The images are processed utilizing cross-correlation method with interrogation area size of $64 \times 64$ pixels $^{2}$ with $50 \%$ overlap resulting in a $2.88 \mathrm{~mm}(12.5 \%$ of blade tip chord length) vector spacing. Moving average validation is conducted on the vector maps before calculating the vector statistics. The flow is seeded using a fog generator located at the inlet of wind tunnel fan. The measurements are conducted at a jet free stream velocity of $11.5 \mathrm{~m} / \mathrm{s}$ while the turbine is rotating at $1348 \mathrm{rpm}$ corresponding to a TSR $\approx 6$, which is the design TSR of the rotor. 
Figure 6 shows a picture of the test facility while performing phase-locked PIV measurements at rotor phase $0^{\circ}$.
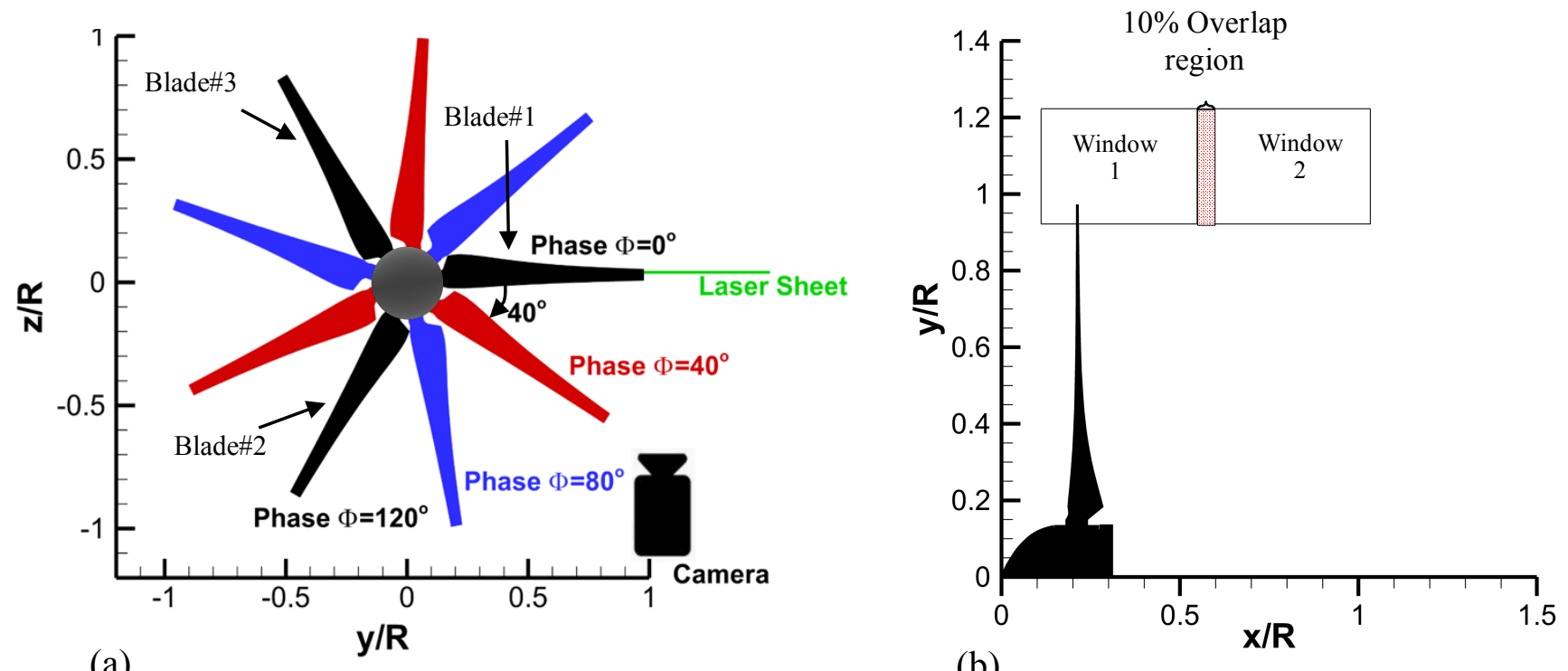

(b)

Figure 4 (a) Phase definitions and sample three phases, (b) PIV measurement domain.
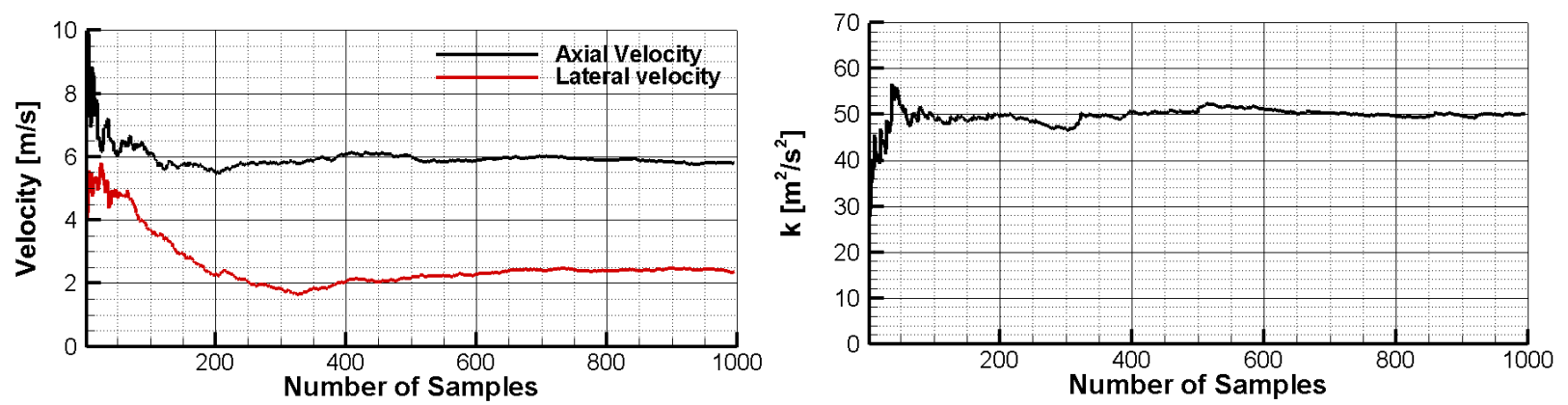

Figure 5 Convergence plot for two measured velocity components (left) as well as for turbulent kinetic energy (right) using samples from a grid point in window 1, for phase 90 and near the vortex core. 


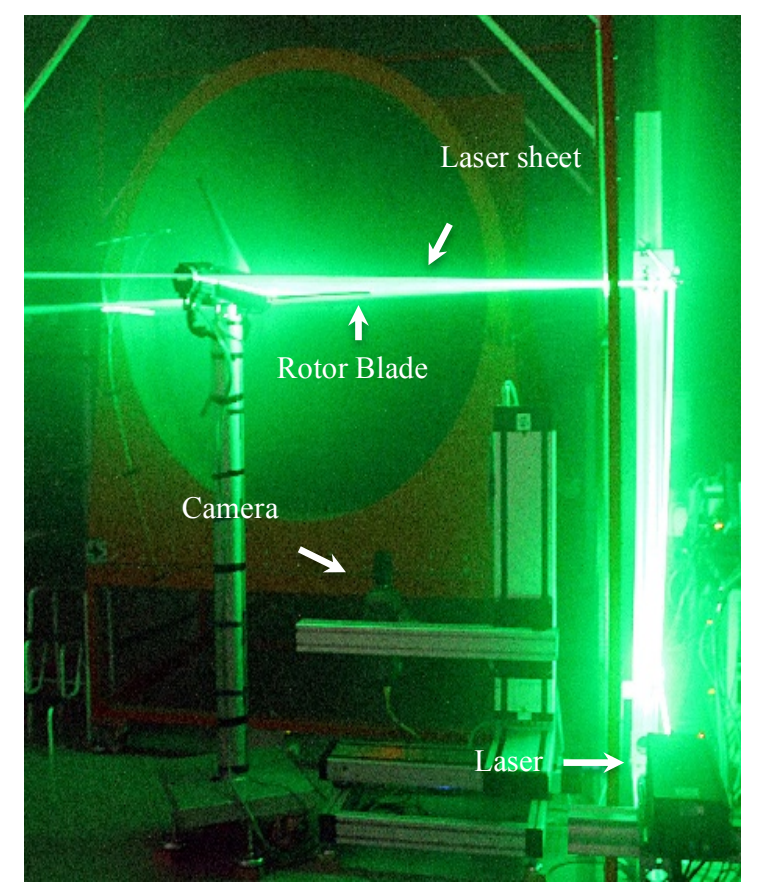

Figure 6 Picture of the facility while performing phase-locked PIV measurements.

\section{RESULTS}

\section{Flow Field Characteristics Near the Tip}

In order to give an orientation for the reader before presenting all the PIV data, Figure 7a shows a sample PIV raw image superimposed by phase-averaged vortex-induced velocity vectors on window 1 (see Figure 4b) for the baseline case (i.e. no winglet) at rotor phase angle $\Phi=36^{\circ}$. Corresponding phase-averaged axial velocity $\bar{u}$ and out-of-plane vorticity $\overline{\Omega_{z}}$ distributions are shown in Figures $7 \mathrm{~b}$ and $7 \mathrm{c}$, respectively. The vortex-induced velocity vectors are obtained by subtracting average vortex core convection velocity values from the actual measured velocity components [24]. Vortex centers are defined as the points in which the vortex induced velocity vectors are zero, which very well coincide also with maximum out-of-plane vorticity locations. The free stream flow is from left to right. 
The dashed rectangular region represents the position of the blade at phase $\Phi=0^{\circ}$ and the point $\frac{x^{\prime}}{R}=$ $\frac{y^{\prime}}{R}=0$ represents the position of the blade tip at phase $\Phi=0^{\circ}$ (the blade is out of the field of view in the presented phase $\Phi=36^{\circ}$ in Figure 7). The tip vortices, their corresponding trajectories marking the wake boundary as well as their impact on the local velocity and vorticity fields can clearly be observed in Figure 6. As expected, the vortex rotation direction is from pressure side to the suction side of the blade, which generates a high negative out-of-plane vorticity component.
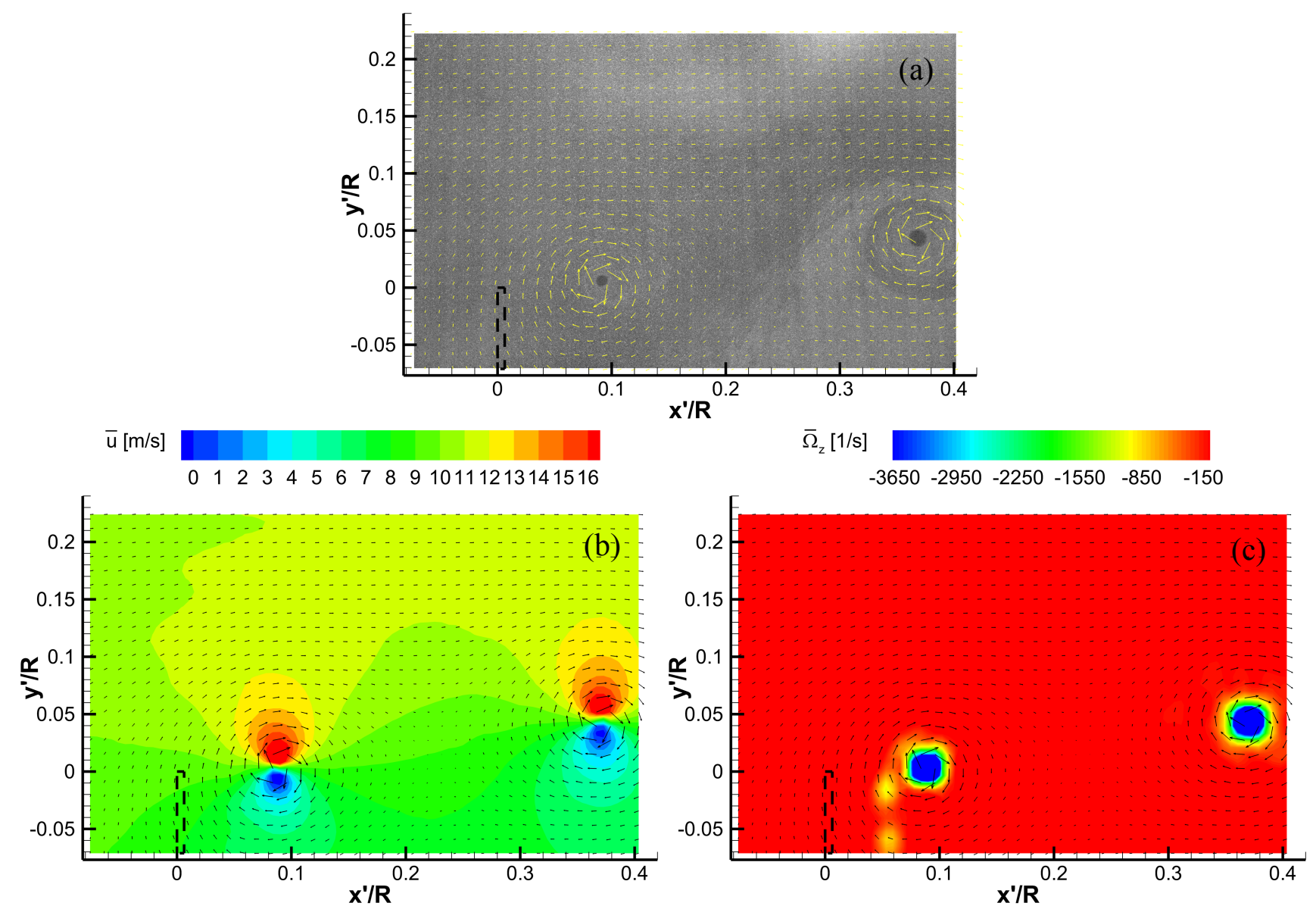

Figure 7 (a) A sample PIV raw image for the baseline case at phase $\Phi=36^{\circ}$, (b) and (c) corresponding phase averaged $\bar{u}$ velocity and out-of-plane vorticity distributions near the blade tip, respectively, superimposed by vortex-induced velocity vectors. The free stream flow is from left to right. The dashed rectangular region represents the blade position at phase $\Phi=0^{\circ} . \quad \frac{x^{\prime}}{R}=\frac{y^{\prime}}{R}=0$ is the position of the blade tip at phase $\Phi=0^{\circ}$. 
Figures 8,9 and 10 show phase-averaged distributions of axial velocity $(\bar{u})$, out-of-plane vorticity $\left(\overline{\Omega_{\mathrm{Z}}}\right)$ and turbulent kinetic energy $(\mathrm{k})$ for 6 different phases of the rotor for the baseline (left) and winglet (right) cases. Here, the turbulent kinetic energy is calculated using the differences between phase-averaged and instantaneous measurements for each phase similar to [24]. Note that the original data set contains 21 phases of the rotor (every 6 degrees from $0^{\circ}$ to $120^{\circ}$ ), but in Figures 8 to 10 , only 6 phases are presented to be concise (every 24-degrees from $0^{\circ}$ to $120^{\circ}$ ). The blades cut the laser sheet plane only at phases $\Phi=0^{\circ}$ and $\Phi=120^{\circ}$ as marked by the white rectangular zones in the figures. In the winglet case a larger region is blocked due to the presence of the winglet.

The PIV data shows the creation and evolution of three distinct tip vortices within the measurement domain. As the phase angle increases, these vortices get convected downstream following and in fact constituting the expanding wake boundary. For example, in $\Phi=24^{\circ}$ in Figure 8 baseline case, the vortex on the left is shed from blade\#1, the vortex in the middle is shed from blade\#2, and the vortex on the right is shed from blade\#3 (the blade numbering is shown in Figure 4a). In order to present a clear discussion regarding these vortices in the following sections we marked them as the first, the second and the third vortex, as shown in Figure $8, \Phi=24^{\circ}$, baseline case. Note that the blade\#1 and the blade\#3 cut the laser sheet at $\Phi=0^{\circ}$ and $\Phi=120^{\circ}$, respectively.

The implementation of the winglet creates significant modifications in the velocity, vorticity and turbulent kinetic energy fields as expected. As is evident from Figure 8, the axial velocity levels around the tip vortices, as well as velocity gradients, are substantially reduced when a winglet is present at the blade tips alluding to the creation of much weaker tip vortex structures within the wake. The downstream convection speed of the vortices, as well as the expansion of the wake boundary, also seem to be getting affected due to the change in the velocity fields. This point will be discussed in a more quantitative manner in the next section. Weakened tip vortices due to the presence of the winglets are also expected to cause an increase in power performance, which was indeed observed near design TSR in previous measurements obtained in the same experimental setup [9]. 
The vorticity distributions presented in Figure 9 show that the vorticity levels within the vortex cores are also significantly reduced in the winglet case confirming the weakening of the tip vortices. Vortex induced velocity vectors, also shown in Figure 9, coincide very well with the vortex centers, where the vortex induced velocity is zero, and the vorticity is a maximum (every third vector is shown for clarity). The results also show the existence of a double vortex shedding process that occurs near the tip when a winglet is present. One of these vortices gets shed from the corner where the pressure side meets the winglet, and the other gets shed from the tip of the winglet. These two distinct vortices can readily be seen in phase $\Phi=24^{\circ}$ in the vorticity contours in Figure 9 at $0.04<x^{\prime} / R<0.12$. The one on the left is shed from the pressure side corner and larger in size compared to the one on the right that is shed from the tip of the winglet. However, the smaller winglet tip vortex has a slightly higher vorticity level around its center. These two vortices constitute a co-rotating asymmetric vortex pair, start rotating around each other and get merged at about $\mathrm{x}^{\prime} / \mathrm{R}=0.4$, which is about 10 tip chords downstream from the rotor blade tip. This characteristic behavior of co-rotating vortices was also observed in previous fixed wing studies (e.g. Devenport et al. [25], Romeos et al. [26]). After merging they get convected as a single but distorted and non-uniform vortex structure, which is also clearly visible in phases $\Phi>24^{\circ}$. The mutual interaction of these two vortices and resultant induced velocities on each other is generating a faster convection of the vortices along the streamwise direction as well as a radially outward convection of the vortices causing a slight expansion of the vortex trajectories towards the freestream, hence a slightly wider wake boundary. More quantitative details will be given in the next section.

Turbulent kinetic energy distributions presented in Figure 10 show that though the levels near the vortex centers are reduced in the winglet case, wider areas are occupied around the vortices. This can clearly be seen for example at $\Phi=72^{\circ}$ and for the first vortex, where in the winglet case the high turbulent kinetic energy region around the vortex seems to be approximately three times larger than that of the baseline case. This is most probably due to the mutual interaction of the double vortex 
structure shed from the blade tip for the winglet case. After the two vortices are merged, the wide region gets smaller and a more uniform distribution can be observed around the vortices.

Figure 11 presents the overall average of all available 21 phases $\left(0^{\circ}\right.$ to $120^{\circ}$ with 6 -degree intervals) for axial velocity (Figure 11a), out-of-plane vorticity (Figure 11b) and turbulent kinetic energy (Figure 11c) for baseline and winglet cases. In Figure 11, data masking due to the presence of blade at the camera field of view is done according to phase $\Phi=0^{\circ}$. The axial velocity distributions presented in Figure 11a clearly show the wake boundary and the expansion of the wake downstream of the turbine both for baseline and winglet cases. Near the wake boundary the lateral gradients (along y) of the axial velocity are very much reduced, and therefore on average, the wake boundary region looks much more diffused. Furthermore, the width of the wake boundary region is not as uniform in the case of the winglet, mainly due to the presence of the double vortex structure up to about $\frac{x^{\prime}}{R}=0.4$ and due to the distorted and non-uniform merged vortex structure after that point. The vorticity distributions shown in Figure $11 \mathrm{~b}$ also show a nice and uniform vorticity region along the wake boundary for the baseline case whereas in the winglet case significant streamwise and lateral non-uniformities are observed. Within the wake boundary centerline, which basically indicates the locus of vortex core center trajectories, the vorticity levels are substantially reduced compared to the no winglet case. Overall average distributions of turbulent kinetic energy presented in Figure 11c illustrate a quite peculiar characteristic. For the baseline case and along the wake boundary centerline there seems to exist a gradual increase in $\mathrm{k}$ levels as one travels downstream. This is of course unexpected and this behavior could be due to increased tip vortex wandering (meandering) near the wake boundary further downstream from the rotor as also reported in [12]. The instantaneous meandering motion of the vortex contributes the velocity field fluctuations and gets reflected in the turbulent kinetic energy field if not appropriately filtered out. Keep in mind that the turbulent kinetic energy is calculated as the difference between phase-averaged and instantaneous vortex fields in this study and the amount of vortex meandering is expected to be observed in the turbulent kinetic energy distributions. We will 
focus on the quantification of the amount of vortex meandering in our upcoming studies. Regarding the case with the winglet, within the very near wake region, $\frac{x^{\prime}}{R}<0.4$, the turbulent kinetic energy levels at the wake boundary are initially high, most probably due to the mutual interaction of the double vortex structure, then a quick decay is observed. However, similar to the baseline case, after the merging of the two vortices the overall averaged turbulent kinetic energy levels again start to steadily increase as one moves downstream though compared to the baseline case the levels are reduced alluding to reduced amount of possible meandering of the tip vortex.

In order to make more quantitative comparisons, Figure 12 presents extracted distributions of overall averaged axial velocity, vorticity and turbulent kinetic energy across the wake boundary at $\frac{x^{\prime}}{R}=0.8$. The distributions clearly show the effects of implementing a winglet, especially within the wake boundary region. Although similar wake and freestream levels are reached away from the wake boundary, i.e. below $\frac{y^{\prime}}{R}<0$ and above $\frac{y^{\prime}}{R}>0.2$, some of the previously discussed effects within the wake boundary are readily observable such as the reduction in the axial velocity gradient across the wake boundary, radially outward displacement of the wake boundary centerline and the reduction of vorticity and turbulent kinetic energy levels on the wake boundary centerline. The wake boundary seems to get pushed radially outwards about $30 \%$ compared to the baseline case. The magnitude of the out-of-plane vorticity and the turbulent kinetic energy levels are reduced about $26 \%$ and $60 \%$, respectively, compared to the no winglet case. The reduction in the axial velocity gradient is about $33 \%$ within the wake boundary. 


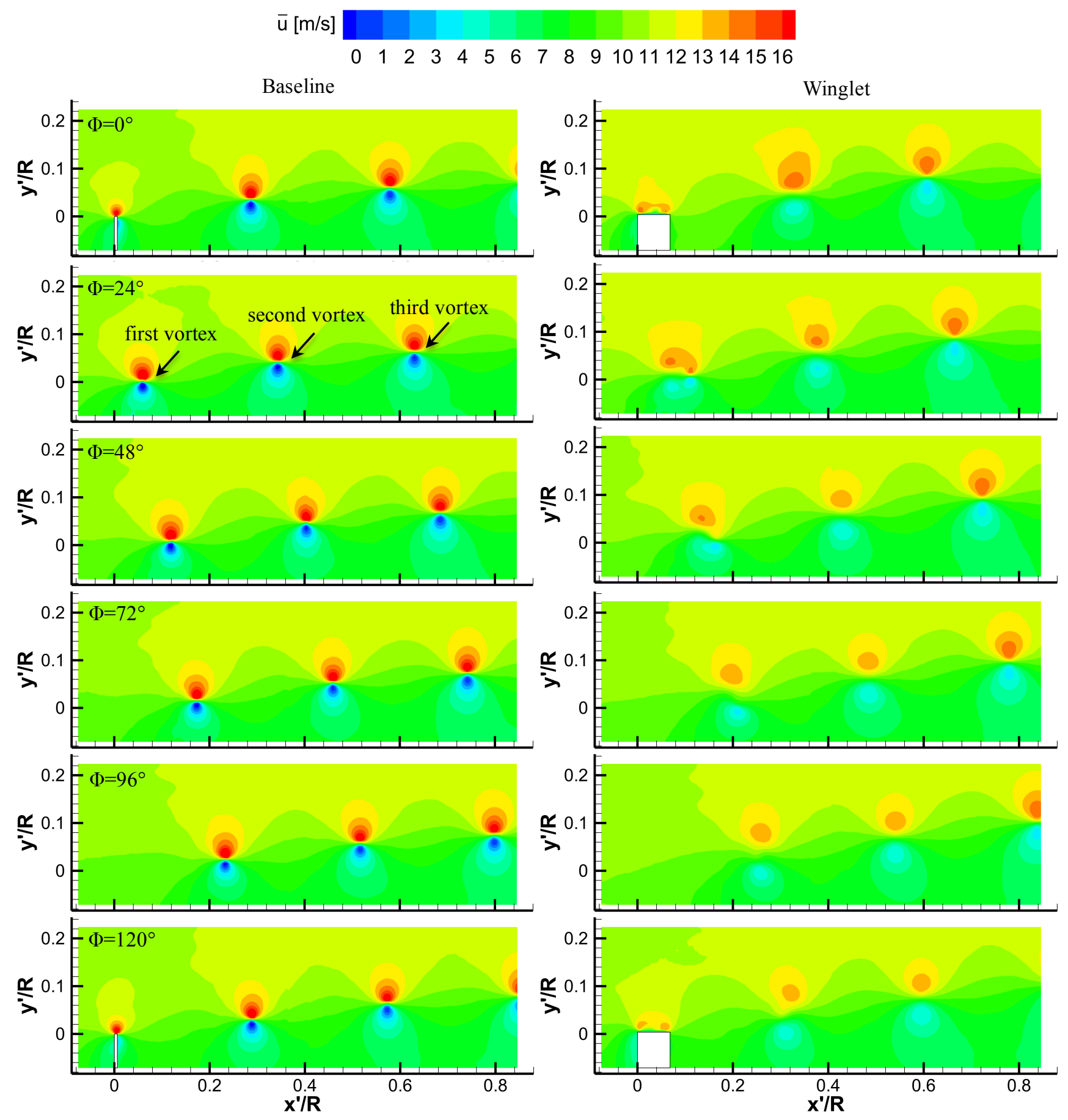

Figure 8 Phase-averaged axial velocity $(\bar{u})$ distributions for rotor phases $0^{\circ}$ to $120^{\circ}$ for baseline (left) and winglet (right) cases. 

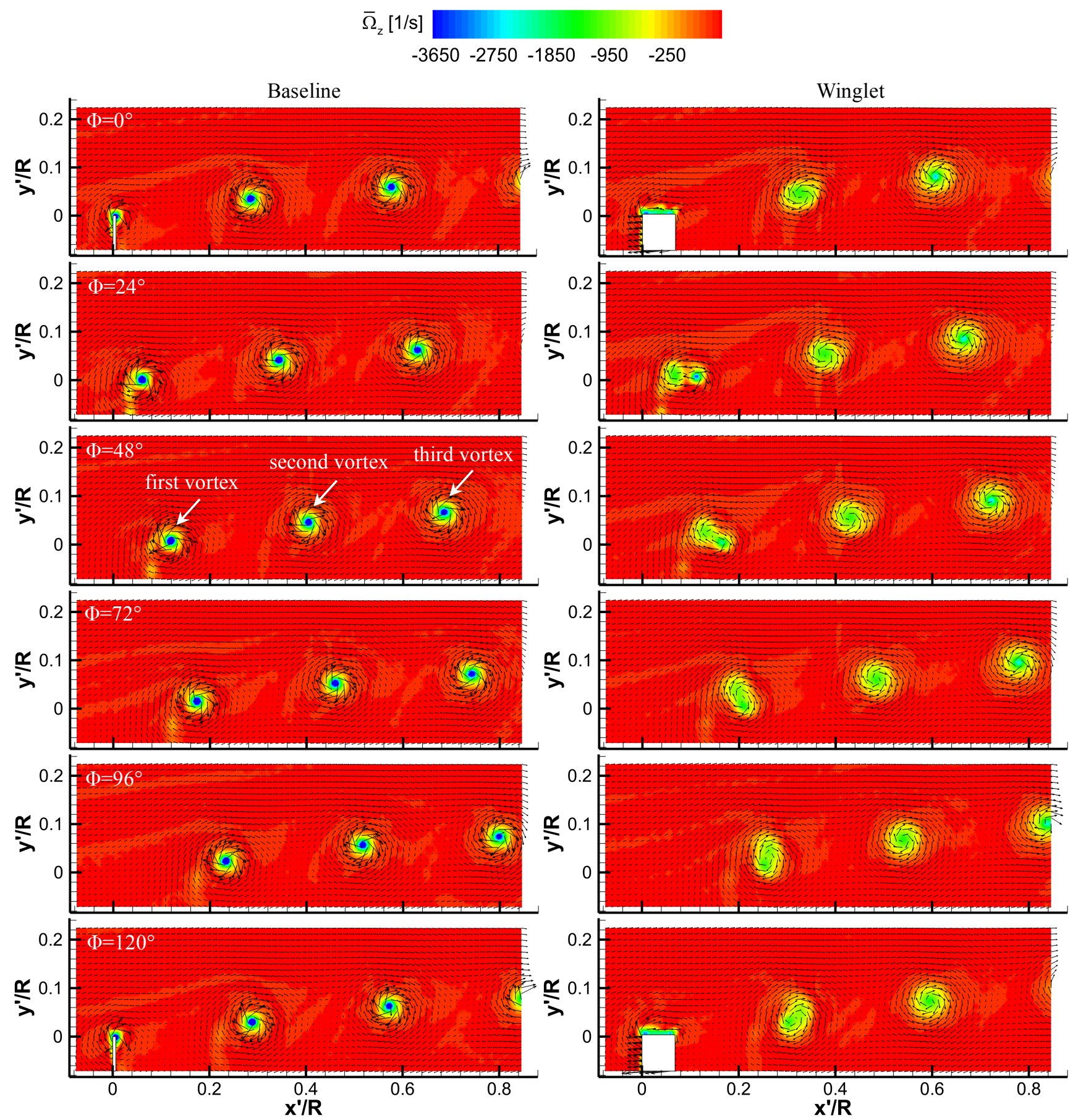

Figure 9 Phase-averaged out-of-plane vorticity $\left(\overline{\Omega_{\mathbf{Z}}}\right)$ distributions for rotor phases $0^{\circ}$ to $120^{\circ}$ for baseline (left) and winglet (right) cases. Vortex induced velocity vectors are superimposed on the distributions. 


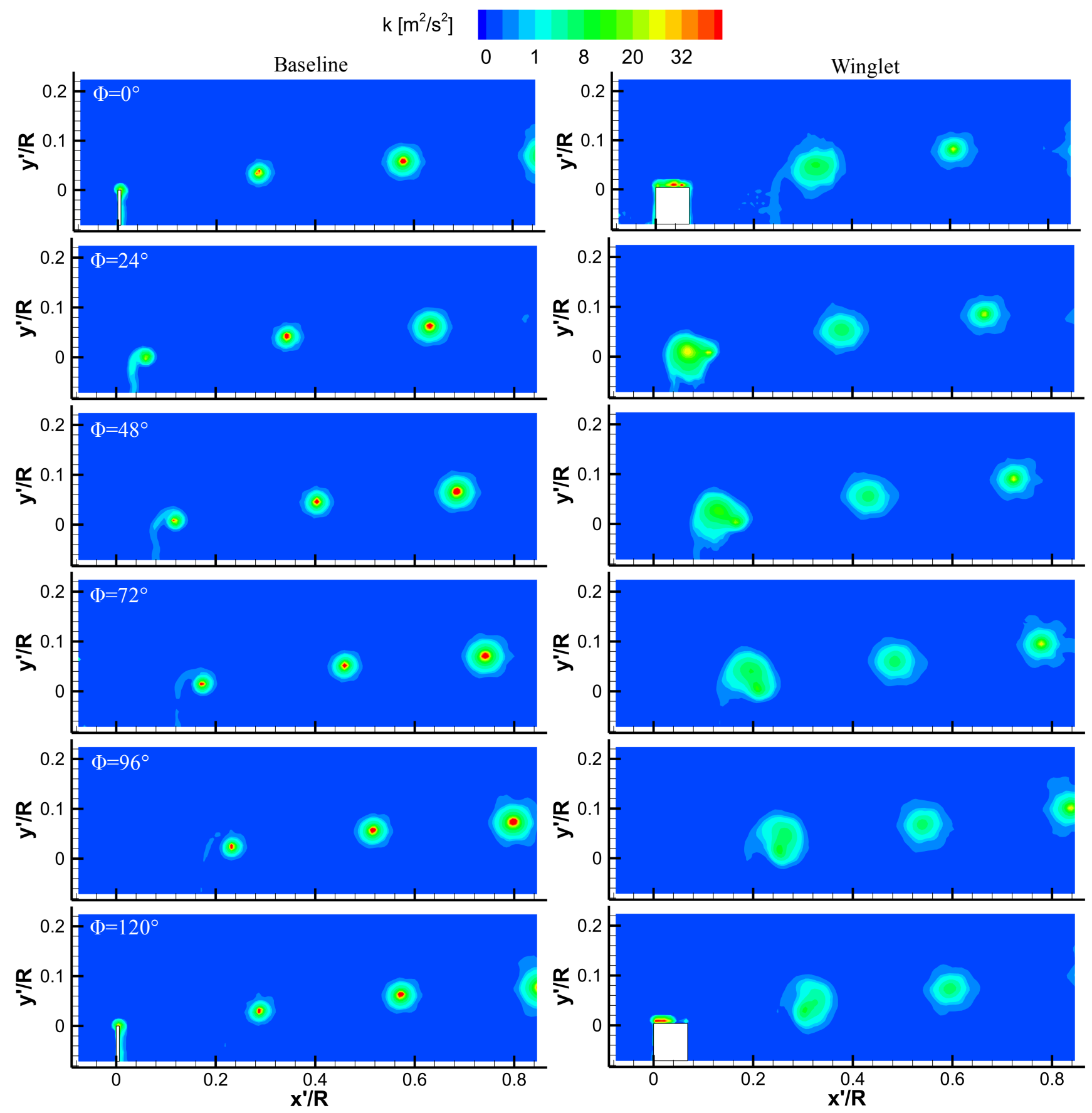

Figure 10 Phase-averaged turbulent kinetic energy distributions for rotor phases $0^{\circ}$ to $120^{\circ}$ for baseline (left) and winglet (right) cases. 

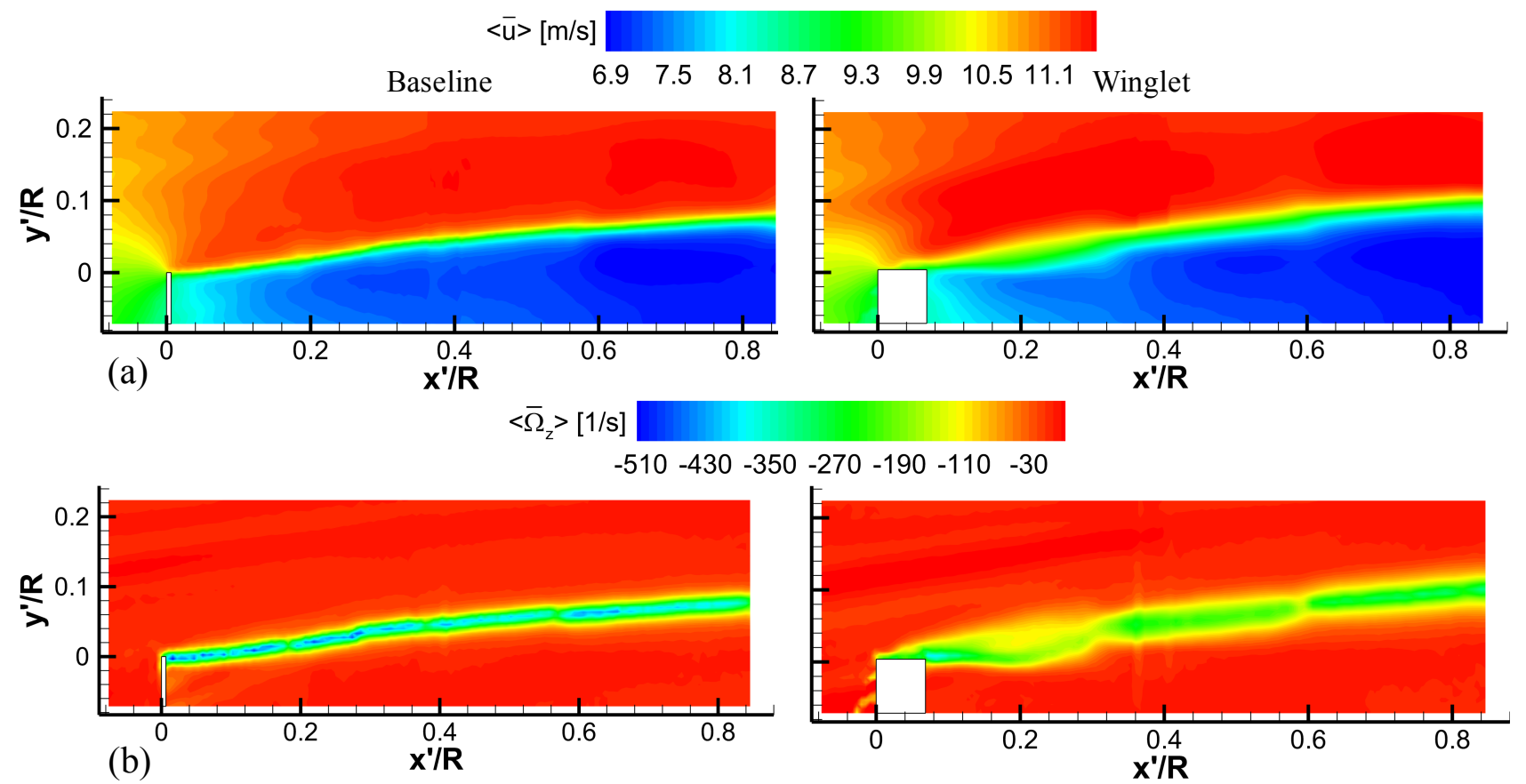

$<\mathrm{k}>\left[\mathrm{m}^{2} / \mathrm{s}^{2}\right]$
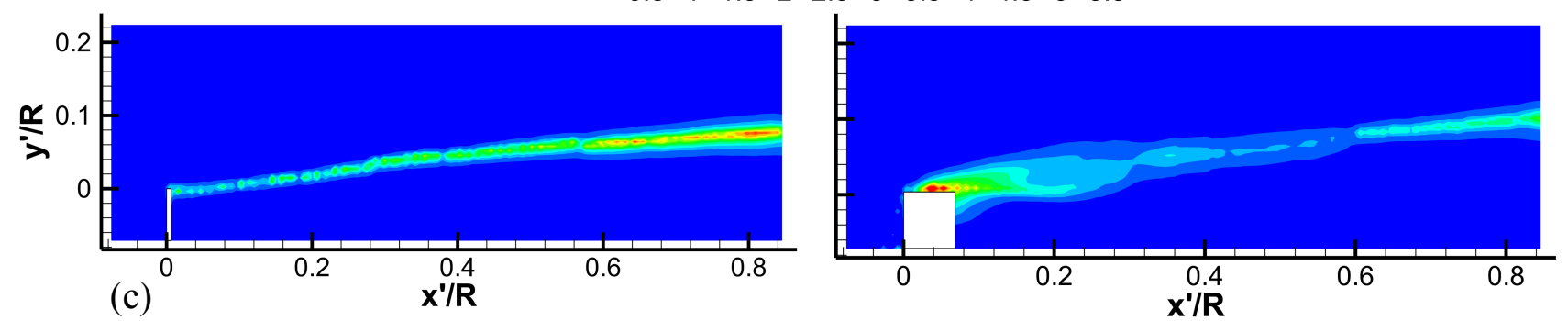

Figure 11 Overall average of 21 phases $\left(0^{\circ}\right.$ to $120^{\circ}$ with 6-degree intervals) for (a) axial velocity, (b) vorticity and (c) turbulent kinetic energy for baseline (left) and winglet cases (right).

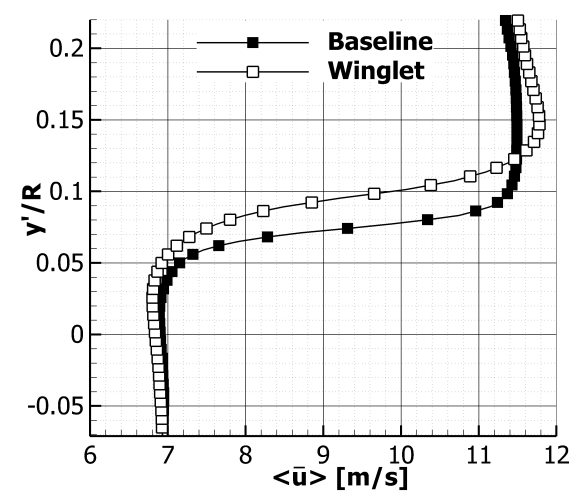

(a)

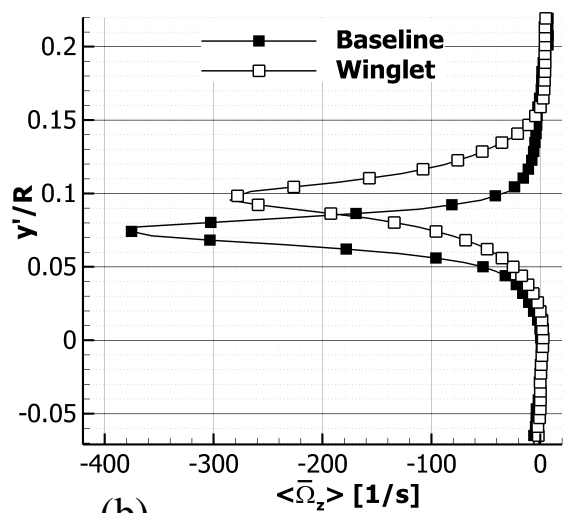

(b)

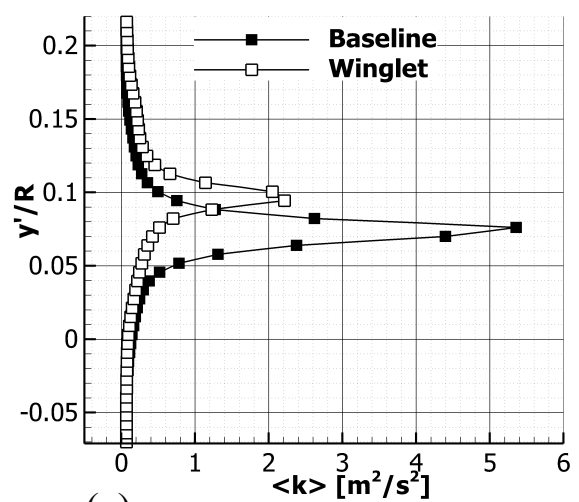

(c)

Figure 12 Data extracted from a vertical line at $\frac{x^{\prime}}{R}=0.8$ from the overall averages of 21 phases $\left(0^{\circ}\right.$ to $120^{\circ}$ with 6-degree intervals) for (a) axial velocity, (b) out-of-plane vorticity and (c) turbulent kinetic energy for baseline and winglet cases. 


\section{Effects on Tip Vortex Characteristics}

Figure 13 shows vortex center positions from vortex age $30^{\circ}$ to $330^{\circ}$ with 30 -degree intervals for the baseline and winglet cases. Vortex age is defined as the blade azimuth angle position after vortex release until the time of measurement. In these measurements, the age of the first vortex is equal to the defined rotor phase angle as the first vortex is shed at rotor phase $0^{\circ}$ when blade\#1 cuts the laser sheet. The age of the second vortex is equal to the rotor phase angle plus $120^{\circ}$ (blade\#2 cuts the PIV measurement plane $120^{\circ}$ prior to blade\#1). Similarly, the age of the third vortex is equal to the rotor phase angle plus $240^{\circ}$. For example, when the rotor is at phase $30^{\circ}$, the first vortex is at age $30^{\circ}$, the second vortex is at age $150^{\circ}$, and consequently, the third vortex is at age $270^{\circ}$ (i.e. the rotor has rotated $270^{\circ}$ since the formation of the third vortex). The vortex center coordinates are the locations with zero

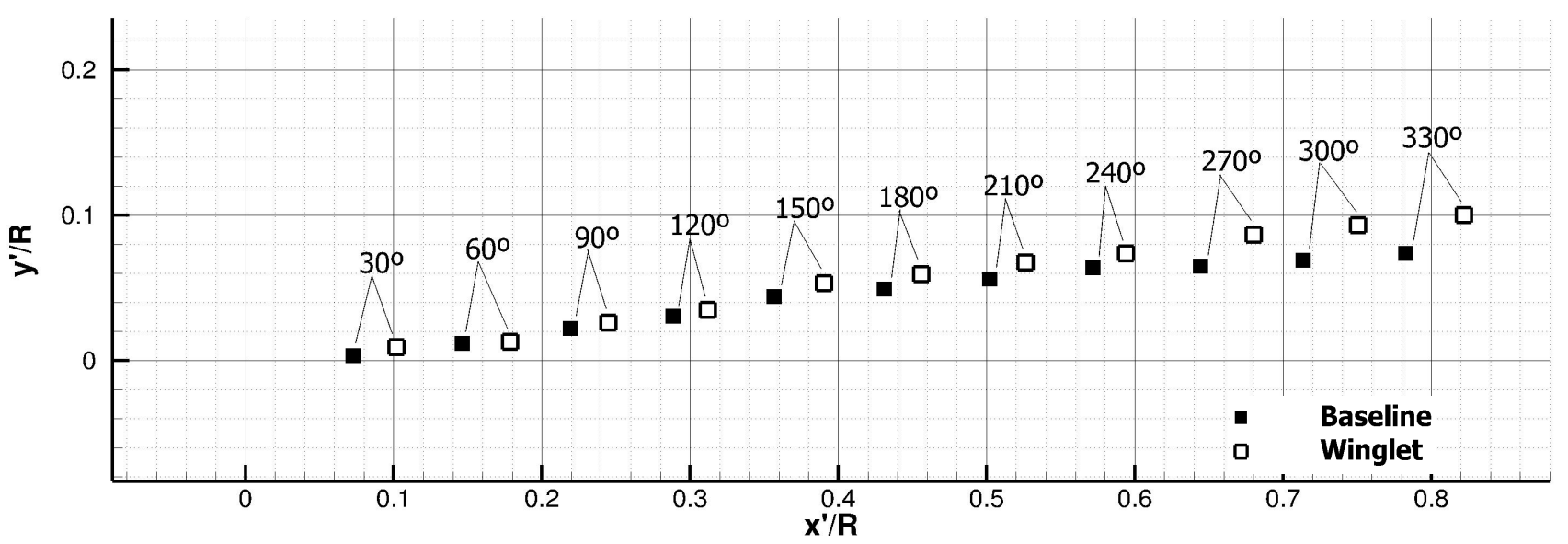

Figure 13 Vortex center positions from vortex age $30^{\circ}$ to $330^{\circ}$ with 30 -degree intervals for the baseline and winglet cases.

vortex induced velocity vectors. It can readily be seen that the tip vortices move further downstream and radially outward when a winglet is present at the blade tips. This downstream and radially outward displacement of the vortices for the winglet case is most probably due to the mutual inductance of the co-rotating vortex pair on each other. For example at $330^{\circ}$, the tip vortex for the winglet case is about $4.5 \%$ further downstream and $30 \%$ further radially out compared to the baseline case (relative to the blade tip, $\frac{x^{\prime}}{R}=\frac{y \prime}{R}=0$ ). This shows that there is more expansion in the wake due to the winglets and this additional expansion is also consistent with literature as a behavior of downwind 
winglets in wind turbines [2]. The small differences observed in the vortex center positions from one blade to the other is most probably due to slight variations in the pitch angle setting of individual blades. Small geometrical differences in blade geometries may also have an effect.

Figure 14 presents a comparison of baseline and winglet cases for the vortex induced swirl (tangential) velocity magnitude, out-of-plane vorticity and turbulent kinetic energy distributions along a horizontal line intersecting the center of second vortex core at rotor phase $60^{\circ}$ (vortex age $180^{\circ}$ ). The horizontal axis is the non-dimensional distance from the vortex core center normalized by the tip chord length of the rotor blade. For both baseline and winglet cases, the vortex induced swirl

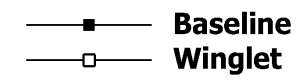

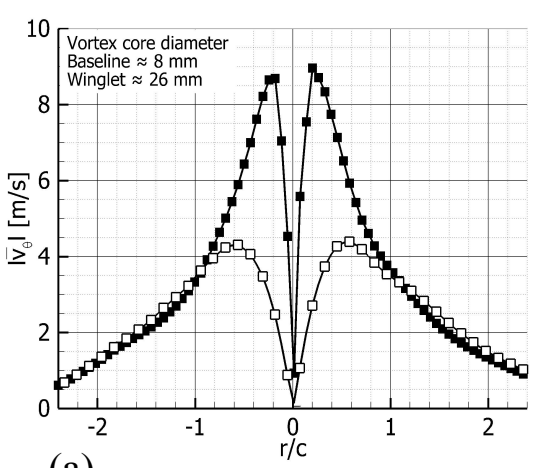

(a)

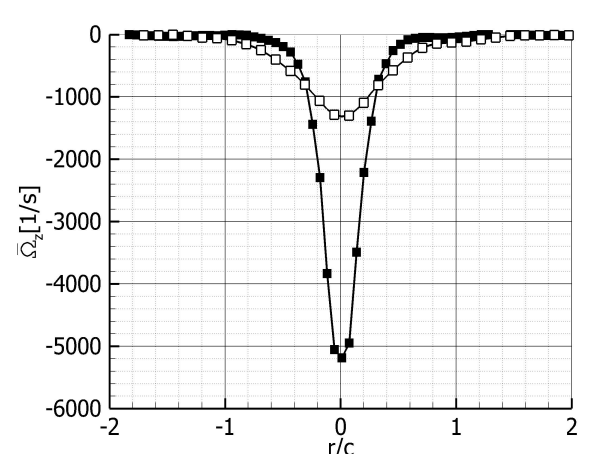

(b)

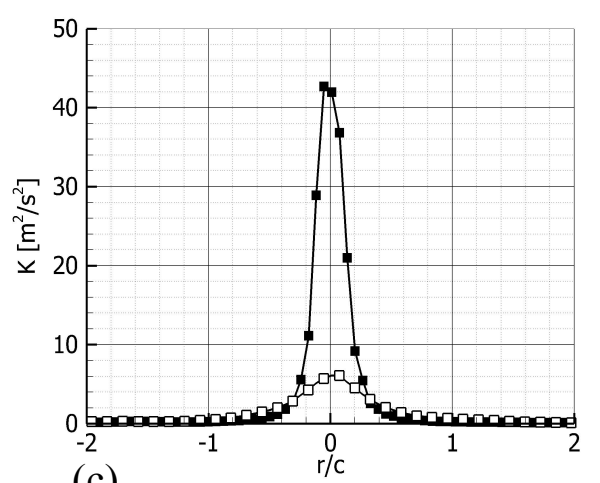

(c)

Figure 14 (a) Vortex induced swirl (tangential) velocity magnitude, (b) out-of-plane vorticity and (c) turbulent kinetic energy distributions along a horizontal line intersecting the center of second vortex core at rotor phase $60^{\circ}$ (vortex age $180^{\circ}$ ). Horizontal axis is the non-dimensional distance from the vortex core center normalized by the tip chord length of the rotor blade.

(tangential) velocity magnitude has a symmetric distribution with respect to the vortex core center (Figure 14a). The vortex core diameter, which is estimated as the location of the maximum value for the induced velocity magnitude, is approximately three times larger when the winglets are used whereas the tangential velocity levels at the vortex core diameter are reduced about $50 \%$ for the winglet case. The ratio of vortex core diameter to the blade tip chord length is about $35 \%$ for vortex age $180^{\circ}$ for the baseline case. By attaching the winglets, this ratio increases to $113 \%$. The vorticity levels within the vortex core are also substantially reduced for the winglet case, as shown in Figure 
$14 \mathrm{~b}$, such that the out-of-plane vorticity magnitude at the viscous core center for the winglet case is about $70 \%$ less than that of the baseline case. Note that the vorticity levels are spread to a larger area around the core due to the increase in the core diameter. Figure $14 \mathrm{c}$ also shows a significant reduction in turbulent kinetic energy levels around the vortex core such that the winglet case is about $80 \%$ less than that of the baseline case and again a slightly larger area is occupied when the winglet is implemented.

Figure 15 presents a comparison of baseline (a) and winglet (b) data with various vortex core models including Rankine [27], Lamb-Oseen [28], Scully [29], original Vatistas [30] and simple Vatistas [31]. The experimental data in this figure is for various phases of the blade corresponding to different vortex ages. In Figure $15 \mathrm{a}$ vortex ages $30^{\circ}$ to $120^{\circ}$ are different phases of the vortex shed from blade 1 and vortex ages $60^{\circ}, 180^{\circ}$ and $300^{\circ}$ correspond to the phase $60^{\circ}$ of blades 1,2 and 3 , respectively. Similarly, in Figure $15 \mathrm{~b}$ vortex ages $150^{\circ}$ to $240^{\circ}$ are different phases of the vortex shed from blade 2 and vortex ages $180^{\circ}$ and $300^{\circ}$ correspond to the phase $60^{\circ}$ of blades 2 and 3 , respectively. Note that vortex ages before $120^{\circ}$ are not presented for the winglet case due to the fact that the double vortices are not yet merged at this phase. For the baseline case, it is seen that all experimental data for different phases and blades collapse on to each other. For the winglet case, all different phases for blade two (vortex ages $150^{\circ}$ to $240^{\circ}$ ) collapse on to each other whereas the distribution for vortex age $300^{\circ}$ (phase $60^{\circ}$ of blade three) shows a deviation starting from $\mathrm{r} / \mathrm{rc}>1.5$ most probably due to slight deviations in the installation of the winglets on the blade tip. The equations for these models are also included here in Table 1 for completeness. The circulation and vortex core radius values that are needed by the models are obtained using the current experimental data.

Results presented in Figure 15a show that the maximum velocity levels at vortex core radius and subsequent decay are generally overpredicted by all models. The Rankine core model, which is the simplest model among the four, overpredicts the maximum swirl velocity up to 2.3 times. The closest results are obtained using the Scully model, which is in fact the same as Vatistas model with $n=1$. A 
further tuning of the Vatistas model with $n=0.85$ shows a significantly improved comparison with the experimental data. Simple Vatistas model with $\alpha=0.7$ also shows an acceptable agreement.

Table 1 Vortex swirl velocity and core expansion models

\begin{tabular}{|c|l|}
\hline Rankine[27] & $V_{\theta}(r)= \begin{cases}\left(\frac{\Gamma_{\infty}}{2 \pi r_{c}}\right)\left(\frac{r}{r_{c}}\right) & r \leq r_{c} \\
\left(\frac{\Gamma_{\infty}}{2 \pi r_{c}}\right)\left(\frac{r_{c}}{r}\right) & r>r_{c}\end{cases}$ \\
\hline Lamb-Oseen[28] & $V_{\theta}(r)=\left(\frac{\Gamma_{\infty}}{2 \pi r_{c}\left(r / r_{c}\right)}\right)\left(1-e^{-1.2526\left(r / r_{c}\right)^{2}}\right)$ \\
\hline Scully[29] & $V_{\theta}(r)=\left(\frac{\Gamma_{\infty}}{2 \pi r_{c}}\right) \frac{r / r_{c}}{1+\left(\frac{r}{r_{c}}\right)^{2}}$ \\
\hline Original Vatistas[30] & $V_{\theta}(r)=\left(\frac{\Gamma_{\infty}}{2 \pi r_{c}}\right) \frac{r_{r_{c}}}{\left[1+\left(r^{2} / r_{c}\right)^{2 n}\right]^{\frac{1}{n}}}$ \\
\hline Simple Vatistas[31] & $V_{\theta}(r)=V_{\theta \max } r / r_{c}\left(\frac{\alpha+1}{\alpha+\left(r / r_{c}\right)^{4}}\right) m, \quad m=\frac{r / r_{c}+1}{4}$ \\
\hline $\begin{array}{c}\text { Vortex core expansion model } \\
\text { (Sant et al.) [32] }\end{array}$ & $r_{c}(t)=\sqrt{4 \alpha \delta_{v} v\left(t+S_{c}\right)}$ \\
\hline
\end{tabular}

For the winglet case (Figure 15b), the Rankine, Lamb-Oseen, and Vatistas with $n=2$ models over predict the maximum swirl velocity at the vortex core radius same as what is seen for the baseline vortex but with less difference with the experimental data. Scully vortex model underpredicts the maximum swirl velocity for the winglet vortex, contrary to what is seen for the baseline case. Original Vatistas model with $n=1.15$ and simple Vatistas model with $\alpha=1$ show the best fit with experimental data. The coefficient values that result in the best fit with experimental data for original and simple Vatistas models are included in Table 2 for both baseline and winglet cases. 


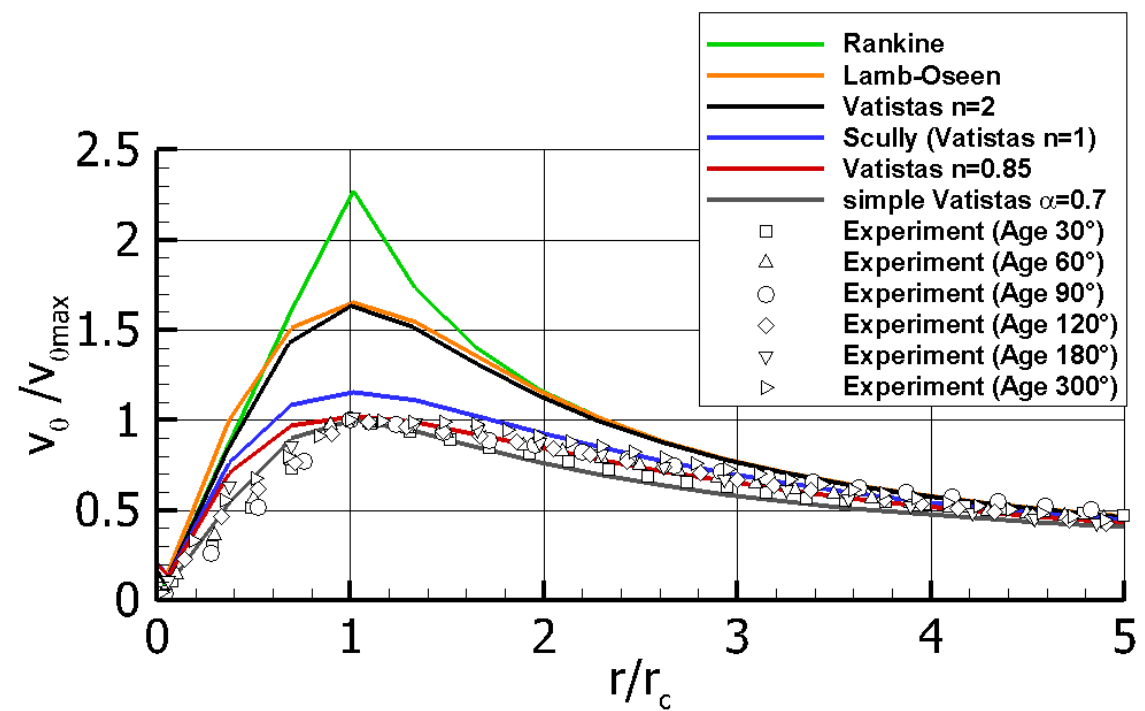

(a)

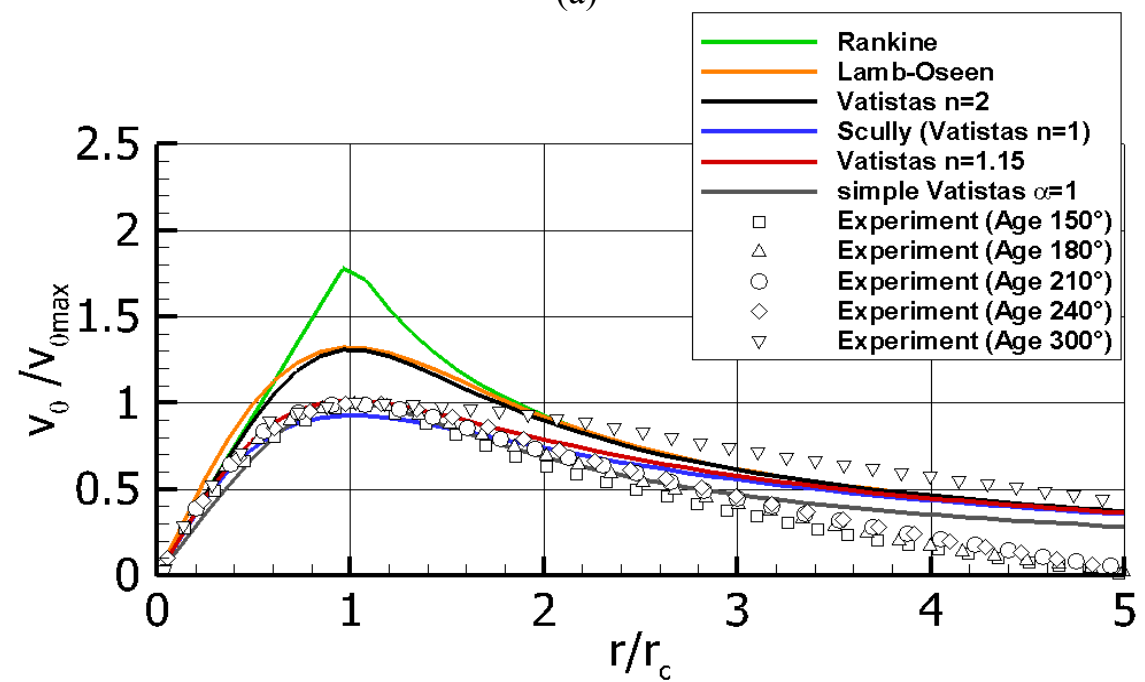

(b)

Figure 15 Comparison of vortex core models with current experimental data for three different phases and ages. Vortex ages $60^{\circ}, 180^{\circ}$ and $300^{\circ}$ correspond to phase $60^{\circ}$ of blades 1,2 and 3 , respectively, (a) baseline and (b) winglet cases.

Table 2 Coefficient values that give the best fit to the experimental data

\begin{tabular}{l|cc} 
& Baseline & Winglet \\
\hline $\mathbf{n}($ Original Vatistas [30], core & 0.85 & 1.15 \\
model) & 0.7 & 1 \\
$\boldsymbol{\alpha},($ Simple Vatistas [31], core & & 20 \\
model) \\
$\begin{array}{l}\boldsymbol{\delta}_{\boldsymbol{v}},(\text { Sant et al [32], core } \\
\text { expansion model) }\end{array}$
\end{tabular}


Figure 16 shows the vortex core growth for the baseline case from vortex age $12^{\circ}$ to $348^{\circ}$ with 6 degree intervals compared to winglet case. The vortex core expansion model of Sant et al. [32] is also presented (Equation 6 Table 1). For the core expansion model, $\alpha$ is used as 1.25643 and $\delta_{v}$, which is a coefficient related to turbulent viscosity and suggested to be in the order of 10 for small-scale rotors, is used as $\delta_{v}=6$ for baseline case and $\delta_{v}=20$ for winglet case. $S_{c}$ is a time offset calculated with $t=0$ at vortex age $12^{\circ}$ for the baseline case and at vortex age $156^{\circ}$ for the winglet case. Regarding the vortex core expansion, the baseline data agrees very well in general with the expansion model of Sant et al. [32] with constants used as given above. The region up to vortex age $80^{\circ}\left(\frac{x^{\prime}}{R}<0.3\right)$ shows some under prediction in a range of $10-20 \%$. The vortex core size evolution for the winglet case shows a reduction in vortex core size up to about vortex age $160^{\circ}\left(\frac{x^{\prime}}{R}<0.4\right)$, mainly due to the merging of the two shed vortices from the tip in this region, followed by a steady increase further downstream. In the

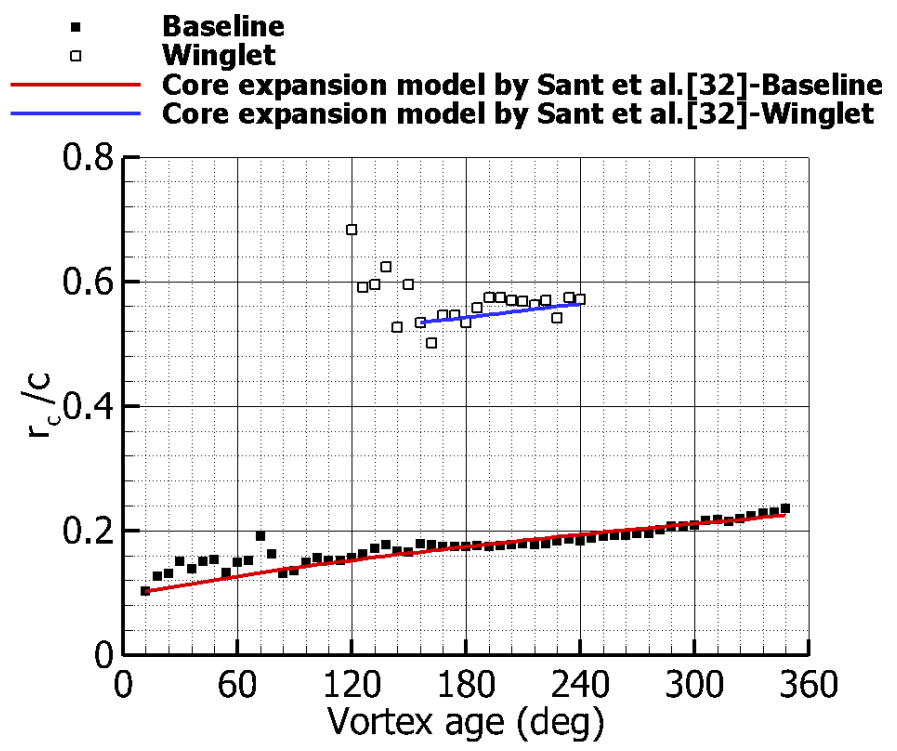

Figure 16 Vortex core growth for the baseline case from vortex age $12^{\circ}$ to $348^{\circ}$ with 6 -degree intervals compared to winglet case. The vortex core expansion model of Sant et al. [32] is also presented.

region where $\frac{x^{\prime}}{R}>0.4$ and for the winglet case, the expansion model shows a good curve fit to the data when a $\delta_{v}$ value of 20 is used, which is about 3 times that of the value used for the baseline case. The vortex core radius for the winglet case is approximately three times larger than that of the baseline case in general. As it is seen in Figure 16, for the baseline case, the vortex core radius to blade tip 
chord length ratio varies from $10 \%$ to $24 \%$ from vortex age $12^{\circ}$ to $348^{\circ}$, respectively. This value was measured about $7.5 \%-10 \%$ in the near wake region of a HAWT in Massouh and Dobrev [12] experiments. Comparing the slopes of the two lines presented in Figure 16 for the baseline and winglet cases the vortex core radius growth rates are $0.0076 \mathrm{~mm} / \mathrm{deg}$ and $0.0083 \mathrm{~mm} / \mathrm{deg}$ for baseline and winglet cases, respectively. Therefore, the tip vortex core radius expands about $9 \%$ faster in the case of winglet compared to the baseline.

\section{Effects on Induced Drag}

For low-speed 3D flows, the induced drag can be estimated using the measured vortex induced velocity vector components as described in Birch et al. [33] and Kusunose [34]. Similar to our current measurement cases, the PIV measurement plane in those studies is also perpendicular to the vortex axis and equation (7) given below is used to estimate the induced drag levels.

$$
D_{i}=\iint_{S} \frac{1}{2} \rho_{\infty}\left({\overline{u_{v}}}^{2}+{\overline{v_{v}}}^{2}\right) d x d y
$$

$\overline{u_{v}}$ and $\overline{v_{v}}$ are phase-averaged vortex induced velocity vectors. This equation is derived from application of the momentum integral theorem, employing the control volume method [33]. The vortex induced velocities are the components of the crossflow velocity in the measuring plane which is perpendicular to the vortex axis. The whole PIV measurement domain is used for the integration

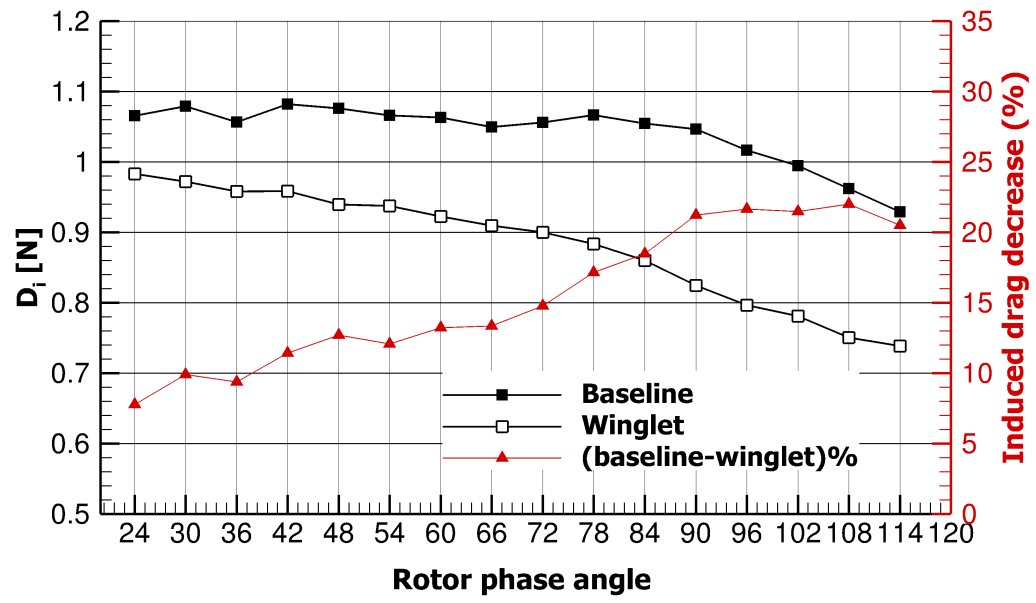

Figure 17 Estimated rotor induced drag for baseline and winglet cases, calculated for rotor phases $24^{\circ}$ to $114^{\circ}$ 
since the domain contains three vortices shed from three consecutive rotor blades. Therefore, the calculated induced drag can be considered as the estimated induced drag for the whole rotor.

Figure 17 shows the estimated induced drag magnitudes for both baseline and winglet cases, calculated for rotor phases of $24^{\circ}$ to $114^{\circ}$. Due to the existence of the blade in the camera field of view for rotor phases of $0^{\circ}, 6^{\circ}, 12^{\circ}, 18^{\circ}$, and $120^{\circ}$, the shadow and data blanking are different for baseline and winglet cases. Therefore, these data are not comparable, and they are not presented.

The results show that, for the baseline case the variation does not change significantly up to $90^{\circ}$ after which the estimated induced drag starts dropping. The main reason for this drop after $90^{\circ}$ is the fact that the third vortex starts moving out of the PIV domain and therefore has reduced effect in the integral term. For the winglet case on the other hand there is continuous drop starting even from the very beginning much before phase $90^{\circ}$ and even when there are three vortices within the measurement domain. This is most probably due to faster dissipation of tip vortices for the winglet case compared to the baseline. In average, there is about $15 \%$ reduction in the estimated induced drag levels when the winglets are attached. This reduction in the induced drag is consistent with the increase in the power production (around 3-4\%) observed in previously performed experiments on the same rotor around the design TSR of 6 [9] when winglets are used.

\section{CONCLUSIONS}

Results of phase-locked 2D PIV measurements near the tip and downstream of a horizontal axis wind turbine rotor are presented. Main focus of the study is to investigate the effects of downwind winglets on the wake flow field near the wake boundary, the effects on the tip vortex characteristics such as the vortex convection, vortex core size, and core expansion as well as the resultant induced drag on the rotor. The results show that winglets initially generate a co-rotating asymmetric double vortex structure near the tip. These vortices then merge together after about 0.2 diameters downstream $\left(\frac{x^{\prime}}{R}=0.4\right)$ and get convected as a single but distorted and geometrically non-uniform entity. Winglets 
cause a faster downstream convection and a radially outward motion of tip vortices, which in turn generate an average wake boundary that is also radially displaced outwards compared to the baseline case, i.e. more wake expansion. The velocity gradients are more diffused, vorticity and turbulent kinetic energy levels are all significantly reduced across the wake boundary near the tip when winglets are implemented. The tip vortex core sizes are three times as big compared to those of the baseline case and within the vortex core vorticity and turbulent kinetic energy levels are reduced more than $50 \%$. Baseline results show consistency with various vortex core velocity field models and core expansion models albeit with adjusted model coefficients for the winglet case. The estimated induced drag reduction, when winglets are implemented, is about $15 \%$.

\section{ACKNOWLEDGMENTS}

This study is supported by METU Center for Wind Energy (METUWIND) and this support is greatly acknowledged. The test turbine was manufactured as a part of a previous project sponsored by The Scientific and Technological Research Council of Turkey (TÜBİTAK) under the Grant No 112M105. This support is greatly appreciated.

\section{REFERENCES}

[1] M.H. Sohn, J.W. Chang, Visualization and PIV study of wing-tip vortices for three different tip configurations, Aerosp. Sci. Technol. 16 (2012) 40-46. doi:10.1016/j.ast.2011.02.005.

[2] J. Johansen, N. Sørensen, Aerodynamic investigation of Winglets on Wind Turbine Blades using CFD, $\quad$ Riso-R-1543(EN). $\quad 1543 \quad$ (2006). http://www.risoe.dtu.dk/da/Knowledge_base/publications/Reports/ris-r-1543.aspx?sc_lang=en.

[3] M. Gaunaa, J. Johansen, Determination of the Maximum Aerodynamic Efficiency of Wind Turbine Rotors with Winglets, J. Phys. Conf. Ser. 75 (2007) 012006. doi:10.1088/17426596/75/1/012006. 
[4] D. Gertz, D. a. Johnson, N. Swytink-Binnema, An Evaluation Testbed for Wind Turbine Blade Tip Designs - Winglet Results, Wind Eng. 36 (2012) 389-410. doi:10.1260/0309524X.36.4.389.

[5] M.A. Elfarra, N. Sezer-Uzol, I.S. Akmandor, NREL VI rotor blade: numerical investigation and winglet design and optimization using CFD, Wind Energy. 17 (2014) 605-626. doi:10.1002/we.1593.

[6] N. Tobin, A. Hamed, L. Chamorro, An Experimental Study on the Effects ofWinglets on the Wake and Performance of a ModelWind Turbine, Energies. 8 (2015) 11955-11972. doi:10.3390/en81011955.

[7] Y. Shimizu, E. Ismaili, Y. Kamada, T. Maeda, Power augmentation of a HAWT by Mie-type tip vanes, considering wind tunnel flow visualisation, blade-aspect ratios and Reynolds number, Wind Eng. 27 (2003) 183-194. doi:10.1260/030952403769016663.

[8] A. Abdulrahim, E. Anik, O. Uzol, Effects of Mie Vanes and Tip Injection on the Performance and Wake Characteristics of a HAWT, in: 34th Wind Energy Symp., American Institute of Aeronautics and Astronautics, Reston, Virginia, 2016: pp. 143-160. doi:10.2514/6.2016-0519.

[9] Y. Ostovan, O. Uzol, Experimental Study on the Effects of Winglets on the Performance of Two Interacting Horizontal Axis Model Wind Turbines, J. Phys. Conf. Ser. 753 (2016) 022015. doi:10.1088/1742-6596/753/2/022015.

[10] I. Grant, M. Mo, X. Pan, P. Parkin, J. Powell, H. Reinecke, K. Shuang, F. Coton, D. Lee, An experimental and numerical study of the vortex filaments in the wake of an operational, horizontal-axis, wind turbine, J. Wind Eng. Ind. Aerodyn. 85 (2000) 177-189. doi:10.1016/S0167-6105(99)00139-7.

[11] J.P. Xiao, J. Wu, L. Chen, Z.Y. Shi, Particle image velocimetry (PIV) measurements of tip vortex wake structure of wind turbine, Appl. Math. Mech. (English Ed. 32 (2011) 729-738. doi:10.1007/s10483-011-1452-x. 
[12] F. MASSOUH, I. DOBREV, Investigation of wind turbine flow and wake, J. Fluid Sci. Technol. 9 (2014) 167-176. https://www.jstage.jst.go.jp/article/jfst/9/3/9_2014jfst0025/_article/cited-by.

[13] P.-Å. Krogstad, J.A. Lund, An experimental and numerical study of the performance of a model turbine, Wind Energy. 15 (2012) 443-457. doi:10.1002/we.482.

[14] P.Å. Krogstad, P.E. Eriksen, "Blind test" calculations of the performance and wake development for a model wind turbine, Renew. Energy. 50 (2013) 325-333. doi:10.1016/j.renene.2012.06.044.

[15] F. Pierella, P.Å. Krogstad, L. Sætran, Blind Test 2 calculations for two in-line model wind turbines where the downstream turbine operates at various rotational speeds, Renew. Energy. 70 (2014) 62-77. doi:10.1016/j.renene.2014.03.034.

[16] P.-Å. Krogstad, L. Sætran, M.S. Adaramola, "Blind Test 3" calculations of the performance and wake development behind two in-line and offset model wind turbines, J. Fluids Struct. 52 (2015) 65-80. doi:10.1016/j.jfluidstructs.2014.10.002.

[17] E. Anik, a Abdulrahim, Y. Ostovan, B. Mercan, O. Uzol, Active control of the tip vortex: an experimental investigation on the performance characteristics of a model turbine, J. Phys. Conf. Ser. 524 (2014) 012098. doi:10.1088/1742-6596/524/1/012098.

[18] A. Abdulrahim, E. Anik, Y. Ostovan, O. Uzol, Effects of tip injection on the performance and near wake characteristics of a model wind turbine rotor, Renew. Energy. 88 (2016) 73-82. doi:10.1016/j.renene.2015.11.030.

[19] M.D. Maughmer, T.S. Swan, S.M. Willits, Design and Testing of a Winglet Airfoil for LowSpeed Aircraft, J. Aircr. 39 (2002) 654-661. doi:10.2514/2.2978.

[20] R.D. Keane, R.J. Adrian, Optimization of particle image velocimeters: II. Multiple pulsed systems, Meas. Sci. Technol. (1991). doi:10.1088/0957-0233/2/10/013.

[21] M. Raffel, C.E. Willert, F. Scarano, C.J. Kähler, S.T. Wereley, J. Kompenhans, Particle Image Velocimetry, Springer International Publishing, Cham, 2018. doi:10.1007/978-3-319-68852-7. 
[22] O. Uzol, C. Camci, The effect of sample size, turbulence intensity and the velocity field on the experimental accuracy of ensemble averaged PIV measurements, in: DLR-Mitteilung, 2001: pp. $1457-1465$.

[23] O. Uzol, Y.-C. Chow, J. Katz, C. Meneveau, Experimental Investigation of Unsteady Flow Field Within a Two-Stage Axial Turbomachine Using Particle Image Velocimetry, J. Turbomach. 124 (2002) 542. doi:10.1115/1.1509077.

[24] B.G. Van Der Wall, H. Richard, Analysis methodology for 3C-PIV data of rotary wing vortices, Exp. Fluids. 40 (2006) 798-812. doi:10.1007/s00348-006-0117-x.

[25] Wi.J. Devenport, C.M. Vogel, J.S. Zsoldos, Flow structure produced by the interaction and merger of a pair of co-rotating wing-tip vortices, J. Fluid Mech. 394 (1999) 357-377. doi:10.1017/S0022112099005777.

[26] A. Romeos, A. Giannadakis, K. Perrakis, T. Panidis, Co-rotating vortex interaction, Aircr. Eng. Aerosp. Technol. 88 (2016) 285-293. doi:10.1108/AEAT-02-2015-0071.

[27] W.J.M. Rankine, Manual of Applied Mechanics, (1858).

[28] C.W. Oseen, Über Wirbelbewegung in Einer Reibenden Flüssigkeit, Ark. Foer Mat. Astron. Och Fys. (1911).

[29] M.P. Scully, Computation of helicopter rotor wake geometry and its influence on rotor harmonic airloads, 1975.

[30] G.H. Vatistas, V. Kozel, W.C. Mih, A simpler model for concentrated vortices, Exp. Fluids. 11 (1991) 73-76. doi:10.1007/BF00198434.

[31] G.H. Vatistas, Simple Model for Turbulent Tip Vortices, J. Aircr. 43 (2006) 1577-1579. doi:10.2514/1.22477.

[32] T. Sant, G. van Kuik, G.J.W. van Bussel, Estimating the angle of attack from blade pressure measurements on the NREL Phase VI rotor using a free wake vortex model:axial conditions, Wind Energy. 9 (2006) 549-577. doi:10.1002/we.201. 
[33] D. Birch, T. Lee, F. Mokhtarian, F. Kafyeke, Structure and Induced Drag of a Tip Vortex, J. Aircr. 41 (2004) 1138-1145. doi:10.2514/1.2707.

[34] K. Kusunose, Development of a universal wake survey data analysis code, in: 15th Appl. Aerodyn. Conf., American Institute of Aeronautics and Astronautics, Atlanta, GA, 1997: pp. 617-626. doi:10.2514/6.1997-2294.

\section{LIST OF FIGURES}

Figure 1. (a) Model wind turbine located at the jet exit of the open jet wind tunnel and (b) the winglets attached to blade tips of the turbine.

Figure 2 Inlet velocity and turbulence intensity distributions $0.5 \mathrm{D}$ downstream of the open jet tunnel. Here $\mathrm{R}$ is the rotor radius. The rotor tip and the tunnel boundary positions are indicated on the image. 7

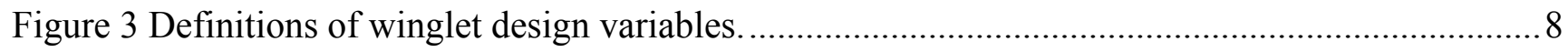

Figure 4 (a) Phase definitions and sample three phases, (b) PIV measurement domain. 10

Figure 5 Convergence plot for two measured velocity components (left) as well as for turbulent kinetic energy (right) using samples from a grid point in window 1, for phase 90 and near the vortex core. .. 10

Figure 6 Picture of the facility while performing phase-locked PIV measurements.

Figure 7 (a) A sample PIV raw image for the baseline case at phase $\Phi=36^{\circ}$, (b) and (c) corresponding phase averaged $\bar{u}$ velocity and out-of-plane vorticity distributions near the blade tip, respectively, superimposed by vortex-induced velocity vectors. The free stream flow is from left to right. The dashed rectangular region represents the blade position at phase $\Phi=0^{\circ} \cdot \frac{x^{\prime}}{R}=\frac{y^{\prime}}{R}=0$ is the position of the blade tip at phase $\Phi=0^{\circ}$.

Figure 8 Phase-averaged axial velocity $(\overline{\mathrm{u}})$ distributions for rotor phases $0^{\circ}$ to $120^{\circ}$ for baseline (left) and winglet (right) cases.

Figure 9 Phase-averaged out-of-plane vorticity $\left(\overline{\Omega_{\mathrm{Z}}}\right)$ distributions for rotor phases $0^{\circ}$ to $120^{\circ}$ for baseline (left) and winglet (right) cases. Vortex induced velocity vectors are superimposed on the distributions.

Figure 10 Phase-averaged turbulent kinetic energy distributions for rotor phases $0^{\circ}$ to $120^{\circ}$ for baseline (left) and winglet (right) cases.

Figure 11 Overall average of 21 phases $\left(0^{\circ}\right.$ to $120^{\circ}$ with 6-degree intervals) for (a) axial velocity, (b) vorticity and (c) turbulent kinetic energy for baseline (left) and winglet cases (right).

Figure 12 Data extracted from a vertical line at $\frac{x^{\prime}}{R}=0.8$ from the overall averages of 21 phases $\left(0^{\circ}\right.$ to $120^{\circ}$ with 6-degree intervals) for (a) axial velocity, (b) out-of-plane vorticity and (c) turbulent kinetic energy for baseline and winglet cases.

Figure 13 Vortex center positions from vortex age $30^{\circ}$ to $330^{\circ}$ with 30 -degree intervals for the baseline and winglet cases. 
Figure 14 (a) Vortex induced swirl (tangential) velocity magnitude, (b) out-of-plane vorticity and (c) turbulent kinetic energy distributions along a horizontal line intersecting the center of second vortex core at rotor phase $60^{\circ}$ (vortex age $180^{\circ}$ ). Horizontal axis is the non-dimensional distance from the vortex core center normalized by the tip chord length of the rotor blade.

Figure 15 Comparison of vortex core models with current experimental data for three different phases and ages. Vortex ages $60^{\circ}, 180^{\circ}$ and $300^{\circ}$ correspond to phase $60^{\circ}$ of blades 1,2 and 3 , respectively, (a) baseline and (b) winglet cases. 25

Figure 16 Vortex core growth for the baseline case from vortex age $12^{\circ}$ to $348^{\circ}$ with 6 -degree intervals compared to winglet case. The vortex core expansion model of Sant et al. [32] is also presented.......26

Figure 17 Estimated rotor induced drag for baseline and winglet cases, calculated for rotor phases $24^{\circ}$ to $114^{\circ}$

\section{LIST OF TABLES}

Table 1 Vortex swirl velocity and core expansion models

Table 2 Coefficient values that give the best fit to the experimental data 